University of Nebraska - Lincoln

DigitalCommons@University of Nebraska - Lincoln

$12-2006$

\title{
Does Seed-Caching Experience Affect Spatial Memory Performance by Pinyon Jays?
}

\author{
B. Lucas Stafford \\ Northern Arizona University \\ Russell P. Balda \\ Northern Arizona University, Russell.Balda@nau.edu \\ Alan Kamil \\ University of Nebraska - Lincoln, akamil1@unl.edu
}

Follow this and additional works at: https://digitalcommons.unl.edu/bioscibehavior

Part of the Behavior and Ethology Commons

Stafford, B. Lucas; Balda, Russell P.; and Kamil, Alan, "Does Seed-Caching Experience Affect Spatial Memory Performance by Pinyon Jays?" (2006). Papers in Behavior and Biological Sciences. 24.

https://digitalcommons.unl.edu/bioscibehavior/24

This Article is brought to you for free and open access by the Papers in the Biological Sciences at DigitalCommons@University of Nebraska - Lincoln. It has been accepted for inclusion in Papers in Behavior and Biological Sciences by an authorized administrator of DigitalCommons@University of Nebraska - Lincoln. 
Published in Ethology 112:12 (2006), pp. 1202-1208; doi: 10.1111/j.1439-0310.2006.01279.x Copyright @ 2006 B. Lucas Stafford, Russell P. Balda, and Alan C. Kamil; published by Blackwell Verlag, Berlin. Used by permission.

Submitted October 24, 2005; accepted June 13, 2006; published online October 20, 2006.

\title{
Does Seed-Caching Experience Affect Spatial Memory Performance by Pinyon Jays?
}

\author{
B. Lucas Stafford, ${ }^{1}$ Russell P. Balda, ${ }^{1}$ and Alan C. Kamil ${ }^{2}$ \\ 1 Avian Cognition Laboratory, Department of Biological Sciences, Northern Arizona University, Flagstaff, AZ, USA \\ 2 School of Biological Sciences and Department of Psychology, University of Nebraska-Lincoln, Lincoln, NE, USA \\ Corresponding author - Russell P. Balda, Avian Cognition Laboratory, Department of Biological Sciences, Northern \\ Arizona University, PO Box 5640, Flagstaff, AZ 86011, USA; email russell.balda@nau.edu
}

\begin{abstract}
Food-storing birds use spatial memory to find previously cached food items. Throughout winter, pinyon jays (Gymnorhinus cyanocephalus) rely heavily on cached pinyon pine (Pinus edulis) seeds. Because of a recent severe drought, pinyon pine trees had not produced a significant seed crop for several years. Therefore, 1- and 2-yr-old birds never had the opportunity to cache and recover seeds and birds 4 or more years of age had not recovered seeds in 3 yr. This study examined whether natural but extreme variability in experience might result in differences in abstract spatial memory ability during a non-cache recovery test of spatial memory. Three groups of jays were tested for spatial memory ability in an open room analog of the radial arm maze. Two of the groups were 8 months old: young/minimally experienced birds which had 2 months of experience in the wild, while young/ experienced birds had 5 months of experience in their natural habitat. The third group, adult, consisted of birds more than $3 \mathrm{yr}$ old, with at least $3 \mathrm{yr}$ of experience in their natural habitat. This was the only group with experience caching pine seeds. All three groups performed equally and well above chance. This suggests that spatial memory is fully developed by 8 months of age and is not affected by extensive experience in the wild.
\end{abstract}

\section{Introduction}

Scatter-hording animals cache food in multiple, spatially distinct locations and later recover these caches as food as needed (Vander Wall 1990). The success of this foraging strategy depends on an animal's ability to cache food such that it remains intact (i.e. not pilfered or degraded) and then to recover these caches when needed.

Most species display species-typical behavioral patterns when caching and recovering food. The ontogeny of species-typical caching behaviors has been well studied in several scatter-hoarding birds including pinyon jays (Gymnorhinus cyanocephalus; Stotz 1991; Stotz \& Balda 1995); crested (Parus cristatus) and willow (Parus montanus) tit (Haftorn 1992); marsh tits (Parus palustris; Clayton 1992, 1994); and Clark's nut- crackers (Nucifraga columbiana; Dimmick 1993). These studies report that the onset of caching behaviors occurs at a specific age (typically around the time of nutritional independence) and is apparently independent of extensive experience. These initial behaviors are then influenced by experience and develop into species typical behaviors.

Few studies have examined the developmental progression of cache recovery accuracy. Clayton (1992, 1994) experimentally separated the effects of age and experience on recovery accuracy in marsh tits. She found that accuracy is primarily a function of age but can also be influenced by experience, and is fully developed by 1 mo. However, Dimmick (1993) found that Clark's nutcrackers' cache recovery accuracy improves throughout the first $3 \mathrm{yr}$ (he did not separate the effects of age and experience). Both the 
marsh tit and Clark's nutcracker rely on spatial memory to find the hidden caches (Clark's nutcracker: Kamil \& Balda 1988; marsh tit: Sherry et al. 1981). Clark's nutcrackers make more caches than marsh tits and recover them over a longer period of time (Vander Wall 1990). Therefore, Clark's nutcrackers may rely more heavily on spatial memory to recover caches than marsh tits. If spatial memory abilities are affected by age or experience this might explain why Clark's nutcrackers' and not marsh tits' recovery performance increased over time. We asked whether natural, but extreme variability in experience might result in differences in abstract spatial memory ability.

Like the Clark's nutcracker, pinyon jays cache thousands of pine seeds each fall when they are available. Seeds are cached in individual subterranean sites, and pinyon jays rely on spatial memory to recover their caches 4-7 months later (Balda 2002). Pinyon jays use the cached seeds to survive the unproductive winter months, breed early in the spring, and feed their nestlings before other food sources are available (Balda \& Bateman 1971). The absence of these food stores would likely have dramatic effects on fitness.

Young pinyon jays do show a developmental set of behaviors that occur even when preferred caching items are absent. In the wild and in cages, pinyon jays from 3 weeks of age onward begin manipulating a large range of items they find during extensive exploratory behaviors. These items are often stuck into the substrate and then immediately withdrawn, carried to a new site, and recached and withdrawn. This behavior has been labeled "play caching" by Stotz (1991). Items handled in such a manner include rabbit (Sylvilagus sp.) scat, roofing nails, unripened juniper berries, tree bark, and dead insect exoskeletons. During a young pinyon jay's first 3 months of life, few if any natural (edible) foods are available for caching. Berries, nuts and seeds are not present, and pine cones are small and covered with pitch. At this time in the annual cycle, all members of pinyon jay flocks are searching and eating arthropods which are abundant because of summer rains. During these summer months, we (RPB and colleagues) have observed pinyon jays over 100s of hours and have never observed them caching.

An experience-dependent mechanism is particularly intriguing because during times of drought and during non-mast years (average: 5 of $7 \mathrm{yr}$ ) pinyon pines do not produce seeds and during these years birds do not gain experience caching and recovering them (Marzluff \& Balda 1992; Balda 2002).
Because of a severe drought in the south-western United States, no significant pine cone crop was produced from 2000 through 2002. Therefore, at the time of this experiment, 1- and 2-yr-old birds had no experience caching and recovering pine seeds. This lack of experience might result in these birds being inefficient at recovering their hidden seeds. Thus, during future significant cone crops they would almost certainly have a lower fitness than those that were efficient. Furthermore, the fitness consequences would be more pronounced if a sensitive phase were present and birds born during years without seeds were unable to acquire the necessary experience. Because of the probable negative fitness consequences of an experience-dependent mechanism and the lack of such a mechanism in other food-storing birds, we hypothesized that limited experience, within an ecologically relevant range, would have no effect on the spatial memory abilities of pinyon jays.

In this experiment we tested birds from different cohorts, with different experiences caching pine seeds. Cache/recovery procedures could not be used because Stotz (1991) found that young birds without experience caching in the wild will not cache in the laboratory. We used an open field analog of the radial arm maze as a measure of abstract spatial memory ability (Kamil \& Balda 1988) and utilized the natural environmental conditions to obtain birds of three different age and experience levels from the wild. An ongoing long-term population study of several banded flocks allowed us to select birds from cohorts of known age.

There were three groups in the experiment, all birds having been captured in 2002. The young/minimally experienced group (yng/minexp) had been captured approximately 2 months after they fledged, before the few cones that were produced that year were ripe enough to open. Members of this group had no experience caching or recovering pine seeds but had "play cached." The young/experienced group (yng/ exp) spent 5 months in their natural habitat within their natal flock before being captured and had "play cached" and may have had limited experience foraging for cones and possibly caching some seeds. The adult group (adult) had over 3 years of experience in the wild and was the only group to have foraged during a large pine cone crop that occurred in 1999. These adult birds had almost certainly cached and recovered thousands of seeds 3 years earlier.

This design took advantage of the "natural experiment" presented by the drought. The two groups of birds of the same age $(y n g)$ but different experience 
levels (exp \& minexp) allowed for separation of the effect of small amounts of experience early in life, while the adult group provided a comparison with highly experienced birds. The inclusion of the two young groups was important because pine seeds are first harvested and cached during the sixth or seventh months of life, when we might expect to see the existence of a sensitive phase. This is also the time when true cache/recovery behaviors are first expressed (Stotz 1991). If there is a sensitive phase for the development of spatial memory abilities that is dependent on caching and recovery behavior, and this phase occurs during the first 5 or 6 months of age, we predicted that the yng/exp group would outperform the $y n g /$ minexp group in the radial arm maze.

Using these "natural" treatment groups did not allow us to fully separate the effects of caching experience beyond the age of 6 months (the amount of experience possessed by the yng/exp group). However, we did have groups at opposite ends of the age and experience ranges: young birds, with the minimal amount of experience a bird might receive in the wild (yng/ minexp) and fully mature adults with extensive experience in the wild (adult). We predicted that if there is an effect of age or experience on spatial memory, the adult group would outperform the $y n g /$ minexp group in the radial arm maze.

\section{Methods}

Fifteen pinyon jays (G. cyanocephalus) participated in this experiment, five from the $y n g /$ minexp group, five from the $y n g / \exp$ group, and five from the adult group. The young birds were hatched in mid-June. The yng/minexp group was captured in mid-August, and the $y n g / \exp$ and adult group were captured in mid-November. All birds were naive to the experimental room and radial maze procedure.

All birds were individually caged and held under a 10:14-h light-dark cycle. Food consisted of chicken starter, gray-stripe sunflower seeds, parrot pellets and either fruit or mealworms. Clean water was provided ad libitum and birds were weighed on alternate days. The birds were reduced to $90 \%$ of their free-feeding weight through close monitoring of their feeding regimes during the experiment.

The experimental design was an open field analog of the radial arm maze. A detailed description of the apparatus can be found in Kamil et al. (1994). The experiment took place during February and March of 2003. The experimental room consisted of a raised plywood floor in which 12 evenly spaced holes were ar- ranged in a circle with a diameter of $114 \mathrm{~cm}$. A sandfilled cup or a wooden cap could be placed in each of the 12 holes. A 1-meter high perch was placed in the center of the circle and an array of landmarks was placed on the floor and several posters were placed on the walls. The room also contained a one-way window for observation, a porthole through which birds entered and left, and a door for human access.

This experiment consisted of three phases: acclimation, pretraining, and acquisition. Acclimation consisted of two 30-minute sessions followed by at least three 15-minute sessions performed on consecutive days. During the first 30-minute session, the birds were individually placed in the experimental room with all holes closed and no food present. After 30 minute the bird was removed. During the second 30-minute habituation session, all holes were open (i.e. contained a sand filled cup) and 20 whole pinyon pine seeds and 10 pieces of seeds $(1 / 2$ of a hulled seed) were scattered on the floor. An additional whole seed was placed on the central perch.

During the 15-minute acclimation sessions all holes were open and 10 whole pine seeds and 10 pieces of hulled seeds were scattered on the floor. To pass the acclimation phase of the experiment and move on to the pretraining phase, a bird had to land on the floor of the room and eat a food item three times. Therefore, each bird underwent at least three 15-minute acclimation sessions.

During all three pretraining stages, sand-filled cups were placed in eight randomly selected holes with a maximum of three adjacent holes containing cups. The other four holes were plugged with a wooden cap. During pretraining stage 1 , one-half of a hulled pine seed was placed on top of each cup. During pretraining stage 2 , one-half of a hulled pine seed was half buried in each sand filled cup. During pretraining stage 3 , the seed was completely buried. To complete a pretraining stage, a bird had to consume all eight rewards. If the bird was inactive for 15 consecutive minutes, the stage was ended and repeated the following day with a new set of holes open. When the three pretraining stages were completed, a bird proceeded to the acquisition phase.

The acquisition phase was a 4/8 win-shift paradigm. Trials were divided into two stages; a pre-retention stage and a post-retention stage separated by a 5-minute retention interval. During the pre-retention stage, four holes were open and one-half of a hulled pine seed was buried in each of the sand-filled cups. The four open holes were randomly selected with the criterion that no more than two adjacent holes were open. The seed was buried less than $1 \mathrm{~cm}$ 
deep in the center of the cup. The sand-filled cup's surface was then smoothed to remove any visual cue of the buried item. The other eight holes were capped with a wooden plug. The bird was allowed to recover the four rewards and then left the room through the portal.

The bird then remained outside of the room in its cage for the 5-minute retention interval. During the retention interval, all signs of digging from the preretention stage were removed, four additional holes were opened, and one-half of a pinyon pine seed was buried in each of these four holes. After this retention interval, the bird reentered the room for the post-retention stage.

Of the eight open holes, the four "new" holes now contained a buried food reward while all four "old" holes were empty. The four "new" open holes were randomly selected with the criterion that no more that two adjacent holes were "new" and that no more than three adjacent holes ("old" and "new") were open. This stage continued until all rewards had been recovered or after six unique holes were probed. Limiting the number of holes probed required the birds to remember which four holes they had probed during the pre-retention stage and probe the alternate four holes in the post-retention stage to receive the maximum rewards in a single session. The order and location of holes that were probed was recorded during the pre- and post-retention stage. For any particular bird, each hole contained a seed an equal number of times throughout the experiment. Thus, over the course of the experiment all holes were equally likely to contain a seed.

A 10-minute time limit was set for both stages (preretention and post-retention) of the acquisition trials. If a bird did not complete either stage within 10 minute of entering the room, the trial was ended and repeated the following day (with a new set of randomly selected holes).

Birds were given one trial per day, 6 days a week and fed 30 minute after completion. Forty-five acquisition trials were completed in this experiment.

\section{Results}

Most birds completed the acclimation phase in the minimum number of trials (5). However, one bird took nine trials to reach the criterion. Seven of the 15 birds completed the pre-training phase in the minimum three trials $(\bar{x} \pm \mathrm{SD}=4.3 \pm 1.4$ trials, $n=15)$. There was no difference in the number of trials to complete pre-training among the three groups (ANOVA: $F_{2,12}=1.14, p=0.35$ ).
During the acquisition phase of the experiment, all birds readily retrieved the four pre-retention and four post-retention food rewards. Accuracy during acquisition trials was considered to be the percentage of "correct" choices (holes probed that contained a reward in the post-retention stage) during the first four choices of each trial. With eight holes open during each trial and four of them correct, chance performance is $50 \%$. Rare repeat visits to holes were excluded.

The 45 acquisition trials were grouped into nine blocks of five sequential trials. The performance score for each bird was averaged for the five trials in each of the nine blocks. To examine overall accuracy throughout the experiment these data were subjected to a group $\times$ block mixed ANOVA. There were no group differences $\left(F_{2,12}=0.69, p=0.52\right)$ or group $\times$ block interactions $\left(F_{16,96}=0.54, p=0.92\right)$. However, there were differences among blocks indicating improved accuracy $\left(F_{8.96}=20.44, p<0.0001\right)$. All three groups showed rapid and similar improvement away from chance levels (Figure 1). These data were also subjected to an arcsine transformation. However, an arcsine transformation on percentage data made no difference in any of the statistical results presented herein. Therefore, the raw data are presented for ease of interpretation for all relevant statistical tests.

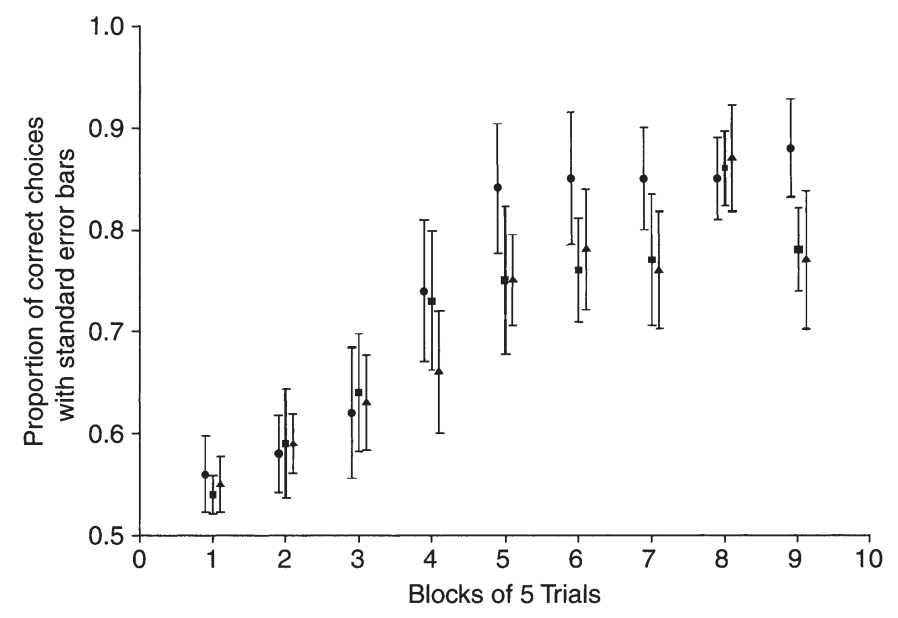

Figure 1. The proportion of correct choices within the first four unique holes probed averaged over consecutive blocks of five trials for all five birds within an age/experience group. Therefore, each data point represents the average scores of 25 trials (five birds during five consecutive trials). Vertical bars represent \pm 1 SE. A score of 0.5 represents a chance performance and a score of 1.0 is a perfect performance. $-y n g /$ minexp; $\mathbf{\square}=$ yng/exp; $\mathbf{\Delta}=$ adult 
Asymptotic levels of performance were examined using the same measure of performance previously described but for only the last four blocks of trials. There were no significant differences among groups (ANOVA: $\left.F_{2,12}=1.17, p=0.34\right)$, blocks $\left(F_{3,36}=1.10\right.$, $p=0.36)$, nor group $\times$ block interactions $\left(F_{6,36}=0.41\right.$, $p=0.87)$.

The speed with which each group acquired the task was determined by the number of blocks required by each bird to reach a criterion of two consecutive blocks with an accuracy of $80 \%$ or better. Birds that did not reach the criterion were given a score of 9. On average $y n g /$ minexp birds took 6.00 blocks of trials, $y n g / \exp =7.8$ and adult $=7.4$. There were no differences among groups in the speed of acquisition (ANOVA: $F_{2,12}=0.99, p=0.40$ ).

To determine if the method of solving the task was different among the three groups, two analyses were performed to determine the post-retention choice pattern and the serial position of errors. The post-retention choice pattern was analyzed by examining the sequence of holes visited during the last 20 trials of the experiment (during the asymptotic phase of the learning curve). The proportion of adjacent holes chosen was calculated for each trial by dividing the number of choices to adjacent holes by the total number of choices minus 1. An adjacent hole choice was considered to be a probe at the next open hole to the left or right of the previously chosen hole. ( 1 was subtracted from the total number of choices because the first choice of each trial could not be adjacent to a previously chosen hole.) There was no difference among groups in the proportion of adjacent holes chosen during the post-retention stage (ANOVA: $F_{2,12}=1.90, p=0.19$ ).

The serial position of errors made was the number of errors made in post-retention corresponding to each of the four holes (ordered serially 1-4) visited in pre-retention during the last 20 trials of the experiment. For each trial, the errors made during post-retention (probing in a hole that had contained a seed during pre-retention and therefore contained no seed during post-retention) were categorized according to the order that hole had been visited during pre-retention. These serial position categories were then summed for each bird. There was no difference among groups in the serial position of errors made (ANOVA: $F_{2,12}=2.00, p=0.17$ ) nor serial position $\times$ group interaction (ANOVA: $F_{6,36}=0.82$, $p=0.56$ ). There was a significant effect of serial position as a result of slightly more post-retention errors made to holes visited early in pre-retention (ANOVA: $F_{3,36}=3.07, p=0.04$ ).

\section{Discussion}

All three age/experience groups performed the radial maze task similarly. No differences were found in the speed at which the radial maze task was acquired or in the asymptotic levels of performance. Furthermore, when all nine blocks of trials were compared, there were no differences among groups, nor were there any significant group $\times$ block interactions. This indicates that all three groups performed at the same level during each block of trials. However, there was a significant effect of block resulting from the sigmoid performance curve indicative of learning the radial maze task (Figure 1). These results suggest that all three groups learned the radial maze task at the same rate and reached the same asymptote in performance.

Analysis of the pattern of hole choice in post-retention and of the serial position of errors suggests that these groups solved the radial maze task in a similar manner.

These findings support the hypothesis that extensive experience, within an ecologically relevant range (first autumn of life), is not necessary for accurate spatial memory abilities of pinyon jays. They also suggest that age (within the range tested) has little or no effect on spatial memory performance.

These results for abstract spatial memory abilities are consistent with the previous research by Clayton $(1992,1994)$ on marsh tits that examined the onset of food storing and cache recovery behaviors with no direct measure of spatial memory. Clayton (1994) major finding was that there was no sensitive phase early in life, but experience clearly had an effect on spatial memory development. Our results are not consistent with Dimmick (1993) who found that the cache recovery accuracy of Clark's nutcrackers does improve with age and experience. This result is surprising because with respect to phylogeny and lifehistory strategy, the pinyon jay is more closely allied to the Clark's nutcracker than to the marsh tit.

This unexpected incongruity may be explained by disparities in the measurements taken. In this study we utilized a radial arm maze analog. This technique is a more direct measure of abstract spatial memory ability than cache recovery accuracy. While good spatial memory abilities are a prerequisite for accurate cache recovery in all three species other factors can limit recovery accuracy. These factors include neophobia as well as proper expression of foraging behaviors and their associated motor skills. Possibly, spatial memory is fully developed very early in life 
in all three of these species but other requirements for accurate cache recovery take longer to fully develop in the Clark's nutcracker than in the marsh tit.

However, the evidence suggests that by 6 months of age, pinyon jays perform similarly to adults both in the wild and in a number of behavioral laboratory tests. Stotz (1991) found that by 6 months of age, pinyon jays in the laboratory and in the wild performed caching and recovery behaviors that were indistinguishable from adults. Similarly, Stafford \& Balda (unpubl. data) found that 6-mo-old pinyon jays in the laboratory had the same behavioral repertoire of foraging behaviors and the same rate of expression of these behaviors as adults (strong preference for pine seeds, bill clicking and the determination of seed quality, seed pouching, and seed opening).

It is also possible that the adult group's performance was impaired by the lack of cache recovery experience for the three previous years. However, the speed of acquisition and level of accuracy the birds acquired in this experiment are comparable to the findings of other radial maze studies involving pinyon jays (Kamil et al. 1994; Gould-Beierle 2000). Therefore, it seems unlikely that degradation in performance occurred at a significant level.

Given the pinyon jays' life history, perhaps it should be expected that spatial memory ability would be fully developed early in life and independent of extensive experience. During years when pinyon pines produce cones, pinyon jays as young as 3 months have the opportunity to cache seeds (These are young birds that are fledged late in the summer, unlike the birds we tested.). However, during periods of drought (a historically regular occurrence in the southwestern USA) and during non-mast intervals, jays may be several years old before they gain such experience. In this evolutionary context, the relatively innate ability to cache and recover seeds would be highly advantageous.

If spatial memory and many foraging behaviors are relatively innate and independent of experience, why is caching behavior not acquired similarly? Stotz (1991) found that even though young birds begin "play caching" at 3 weeks of age, these young pinyon jays require exposure to a large group of jays caching seeds before expressing true caching behavior as observed in older birds. She suggested that young jays require social learning to acquire the caching behavior. Why would selection protect spatial memory and many foraging behaviors from periods when foraging experience cannot be acquired, but not protect the actual act of caching?
The answer may lie in the fact that during most years there are not enough pine seeds to cache and the available seeds are simply eaten. The foraging behaviors found to be relatively innate (and indeed spatial memory itself) are likely to be necessary every year, independent of caching. Every year, pinyon jays use these behaviors to find and eat pinyon pine seeds and other food items regardless of seed availability. Caching itself is not performed every year and therefore would not have the same selective pressures leading to innateness. Selection might act first to protect those abilities necessary for survival every year. If this hypothesis is true, the behaviors required to dig up and recover cached seeds (independent of spatial memory) are also likely to be learned and not innate (i.e. bill probing and swiping).

\section{Acknowledgments}

This research was funded by the National Science Foundation (9882883) and the National Institute of Health (MH61810). Special thanks to Russell Benford, Steven Shuster, Lester Hunt, Chris Nunez, Kate Behn, Bryce Marshall, Sara Stafford, Lisa Swanson, Tom Greene, and Amy Stafford for their advice, support, and hard work. Three anonymous reviewers are thanked for their thoughtful suggestions.

\section{Literature Cited}

Balda, R. P. 2002: The Pinyon Jay. In: The Birds of North America, No. 605 (Poole, A. \& Gill, F., eds.). Philadelphia and Washington, DC: The Academy of Natural Sciences, Philadelphia and the American Ornithologists' Union, pp. 1-32.

Balda, R. P. \& Bateman, G. C. 1971: Flocking and the annual cycle of the pinyon jay, Gymnorhinus cyanocephalus. Condor 73, 287-302.

Clayton, N. S. 1992: The ontogeny of food storing and retrieval in marsh tits. Behavior 122, 11-25.

Clayton, N. S. 1994: The role of age and experience in the behavioral development of food-storing and retrieval in marsh tits, Parus palustris. Anim. Behav. 47, 1435-1444.

Dimmick, C. R. 1993: Life History and Development of Cache-Recovery Behaviors in Clark's Nutcracker. Unpublished PhD Dissertation, Northern Arizona Univ., Flagstaff, AZ. 
Gould-Beierle, K. 2000: A comparison of four corvid species in a working and reference memory task using a radial maze. J. Comp. Psychol. 114, 347-356.

Haftorn, S. 1992: Ontogeny of food storing in titmice $P a-$ rus spp. J. Comp. Psychol. 134, 69-71.

Kamil, A. C. \& Balda, R. P. 1988: The spatial memory of Clark's nutcrackers (Nucifraga columbiana) in an analogue of the radial arm maze. Anim. Learn. Behav. 16, 116-122.

Kamil, A. C., Balda, R. P. \& Olson, D. J. 1994: Performance of four seed-caching corvid species in the radial-arm maze analog. J. Comp. Psychol. 108, 385-393.

Marzluff, J. M. \& Balda, R. P. 1992: The Pinyon Jay: Behavioral Ecology of a Colonial and Cooperative Corvid. T. \& A. D. Poyser, London.
Sherry, D. F., Krebs, J. R. \& Cowie, R. J. 1981: Memory for the location of stored food in marsh tits. Anim. Behav. 29, 1260-1266.

Stotz, N. G. 1991: Social Influences on Caching Behavior of Pinyon Jays. Unpublished Thesis, Northern Arizona Univ., Flagstaff, AZ.

Stotz, N. G. \& Balda, R. P. 1995: Cache recovery behavior of wild pinyon jays in Northern Arizona. Southwest. Nat. 40, 180-184.

Vander Wall, S. B. 1990: Food Hoarding in Animals. The Univ. of Chicago Press, Chicago, IL. 